\title{
Hope and Irrational Beliefs Among Male Prisoners: The Comparative Effectiveness of Existential Therapy (ET) and Acceptance and Commitment Therapy (ACT)
}

\author{
Abolfazl Ziaee ${ }^{1}(\mathbb{D})$, Hamid Nejat ${ }^{1 *}(\mathbb{D})$, Hossein Akbari Amarghan ${ }^{2}$ (D), Elham Fariborzi ${ }^{1}$ ([)
}

\begin{abstract}
${ }^{1}$ Department of Educational Sciences, Mashhad Branch, Islamic Azad University, Mashhad, IRAN
${ }^{2}$ Department of Psychology, Quchan Branch, Islamic Azad University, Quchan, IRAN

*Corresponding Author: hamidnejat54@yahoo.com
\end{abstract}

Citation: Ziaee A, Nejat H, Akbari Amarghan H, Fariborzi E. Hope and Irrational Beliefs Among Male Prisoners: The Comparative Effectiveness of Existential Therapy (ET) and Acceptance and Commitment Therapy (ACT). Electron J Gen Med. 2022;19(2):em349. https://doi.org/10.29333/ejgm/11548

\section{ARTICLE INFO}

Received: 2 Nov. 2021

Accepted: 27 Dec. 2021

\begin{abstract}
Introduction: Examining prisoners' mental health status and providing mental health services to this high-risk group is one of the concerns of psychiatry and health experts in different countries. Also, there are still issues and problems related to criminals and prisoners, especially psychiatric problems as one of the most challenging research areas. This study aimed to compare the effectiveness of Existential Therapy (ET) and Acceptance and Commitment Therapy (ACT) in increasing hope and diminishing irrational beliefs of male prisoners.
\end{abstract}

Materials and Methods: In the present quasi-experimental study, the statistical population consisted of all married male prisoners aged between 25 to 45 years in Mashhad Central Prison in the first half of 2018. Among them, 36 prisoners were selected and then randomly placed in three research groups. Then, the two experimental groups underwent eight separate sessions of ET and ACT. At the beginning and end of the study, all three groups were assessed for hope and irrational beliefs.

Results: Analysis results showed that, in comparison with the control group, changes in the two groups of ET and ACT were significant regarding hope and irrational beliefs of male prisoners. Nevertheless, the effectiveness of ET in increasing hope was higher than that of ACT.

Conclusions: The effectiveness of ET and ACT seems to be almost the same for irrational beliefs (but not for hope) of male prisoners. However, we suggest further investigations to provide a better vision of the effectiveness of these therapeutic approaches for prisoners with special needs.

Keywords: acceptance, commitment therapy, existential therapy, hope, irrational beliefs, prisoners

\section{INTRODUCTION}

Checking the mental health status of prisoners and providing mental health services to this high-risk group is one of the concerns of psychiatry and health experts in different countries. There are still issues associated with criminals and prisoners, particularly psychological problems as one of the most challenging research fields [1]. According to reports published in the last two decades, prisoners experience more mental health problems than the general population due to significant psychological effects, especially in the presence of secondary alexithymia [1-4]. Also, the prison population is inappropriately faced with traumas, mental and psychological deficiencies, and little ability to cope with hardships [5]. Living space plays a key role in human physical and psychological health, and any restrictions on various aspects of this space can increase vulnerability to stress-related psychopathology. Most people interpret the term "prison" as difficult, painful, and torturous conditions and remember it as a terrifying, dark environment, which is not far from reality. The prison environment has unique conditions and characteristics; in general, prison is one of the most stressful and anxious conditions for any human being. The study of various psychological and behavioral components of prisoners is one of the main topics of interest to psychologists and social scientists [6,7].

Hope is one of the variables that prisoners encounter due to their psychological condition and the specific environment of the prison, which needs to be studied. Lack or low level of hope causes a person to feel low efficiency, decreased selfefficacy, and reduced self-esteem and thus finds it pointless to try to make progress in life, resulting in less success [8]. Besides, increasing hope reduces depression, anxiety and stress, and the psychological pressures of injured people. This improves their behavioral functions in society, preventing their high-risk behaviors in society and further spread of the disease [9]. Hope has also emerged as a coping strategy in various areas of education, sports, mental health, and employment [10]. 
Table 1. Summary of group Existential Therapy (ET) sessions

\begin{tabular}{|c|c|}
\hline Sessions & Content of sessions \\
\hline First session & $\begin{array}{l}\text { Admission and welcome, explaining the aims, acquaintanceship among members, describing how the group function, } \\
\text { conducting the pre-test }\end{array}$ \\
\hline Second session & Explaining the concept of self-consciousness and existential anxiety \\
\hline Third session & $\begin{array}{l}\text { Going over the previous session practices and member's expresses and feedbacks about the experience of loss and finally } \\
\text { teaching death anxiety to accept it rather than denying it }\end{array}$ \\
\hline Fourth session & Evaluating and explaining the concept of loneliness \\
\hline Fifth session & Examining the existential strategies for coping with disease recurrence \\
\hline Sixth session & Describing the purpose, responsibility, and freedom in life \\
\hline Seventh session & Assessing strategies for giving meaning to life and coping with the emptiness of life \\
\hline Eighth session & $\begin{array}{l}\text { Summarizing previous material and finding the relation between self-awareness, loneliness, death, purposefulness, and } \\
\text { meaning in life and coping with children's illnesses, as well as post-test implementation }\end{array}$ \\
\hline
\end{tabular}

The area of cognition, thinking, and interpretation is one of the three fields psychologists address when studying the human psyche. Therefore, one can probably assume irrational beliefs as predictors of psychological functioning in prisoners. As per the Rational Emotive Behavior Theory, concerning logical (or illogical) processes in human behavior, man has a number of primary goals, desires, and preferences as the major thinking constituents. In this regard, human beings live more effectively and much better once they are successful in setting goals (goal satisfaction), feel a sense of dominance or selfefficacy (self-satisfaction), stay healthy (health satisfaction), and have approval or less disapproval by people whom they care about (approval and love) [11]. A person uses irrational beliefs, occurring in their mind and affecting their lives, as inapt solutions to their own problems. It is stated that an individual's social and cultural environment is the basis of irrational beliefs [12]. In other words, the information provided by the environment shapes the mental framework of an individual. Further, many fractures and dysfunctional behaviors are triggered by irrational beliefs [11].

All in all, treatment programs and interventions are required for the psychological state of prisoners. In this respect, different therapies have been examined, including Existential Therapy (ET) as one of the psychological methods to improve prisoners' psychological condition. The ET theory includes a set of ideas about human beings and has a philosophical nature [13]. In psychology, the existential approach deals with central and deep issues, such as meaninglessness, loneliness, freedom, and death, for all people, irrespective of religion, culture, race, and ethnicity [14] This approach provokes clients to encounter facets of their lives they have constantly evaded, bravely recognize these unlucky events in their lives, and admit that joy and happiness in life are gained if one can understand the temporary nature of vitality and security in life [13, 14]. ET emphasizes the significance of human life according to their viewpoint on life. This approach involves an attitude to life issues, such as freedom, life and death, finding meaning in life, the concept of meaninglessness, and responsibility for oneself and others [1315].

Acceptance and Commitment Therapy (ACT) is another effective therapeutic approach for the prisoners' mental condition. ACT is one of the new and practical therapies to solve psychological disorders and problems [16]. Its fundamental principles consist of (i) acceptance or desire to experience pain or other disturbing events without making an effort to control them; (ii) value or commitment-based action, pursuing meaningful personal goals prior to removing unwelcome experiences [17]. As an indispensable part of ACT, the patient should be guided into the action path to meet their values. A portion of meetings is designed to generate committed action, which includes therapeutic work, practice, and behavioral change associated with short- and long-term goals. Some psychological barriers are caused due to the efforts toward changing behavior for better adaptation, which are addressed by the ACT treatment process, i.e., acceptance of failure [18].

ACT is partly based on or at least influenced by Eastern mysticism that can be designed in the framework of cognitive approaches and affect the psychological well-being of prisoners [15]. On a larger scale, some of society's values are reflected by prisons. Prisoners are still a portion of human society, irrespective of the crime they have been sentenced to or arrested for. Most of them go through mental disorders, either triggered by physical problems or an adverse psychological effect on the living environment and family. In both cases, counseling and psychotherapy are needed for all prisoners. Further, it is essential to investigate the effectiveness of various therapies in their psychological variables to develop practical therapies on the basis of research evidence. Therefore, the present study seeks to investigate the comparative effectiveness of ET and ACT in increasing hope and diminishing irrational beliefs of male prisoners.

\section{MATERIALS AND METHODS}

\section{Study Design, Participants, and Procedure}

This practical quasi-experimental research conducted as pre-test/post-test, with two experimental groups and a control group. The statistical population of the study included all married male prisoners aged between 25 to 45 years in Mashhad Central Prison, who were sentenced to more than one year in prison and had passed counseling courses and basic psychological classes in the counseling unit. Besides, the presence of an intellectual disability was evaluated and used as exclusion criteria. The statistical sample of the present study consisted of 36 prisoners of the statistical population of the study who were selected by the purposive sampling method and randomly divided into two experimental groups (12 people in each group) and a control group (12 people). The experimental groups underwent eight sessions of intervention (see Table 1 and Table 2).

\section{Measures \\ Adult hope scale}

This 12-item scale is divided into two subscales that include Snyder's cognitive model of hope: (i) Agency (i.e., goal-directed 
Table 2. Summary of Acceptance and Commitment Therapy (ACT) sessions

\begin{tabular}{ll}
\hline Sessions & Content of sessions \\
\hline First session & $\begin{array}{l}\text { Establishing a therapeutic relationship, acquainting people with the research topic, answering the questionnaire, and making a } \\
\text { treatment contract }\end{array}$ \\
\hline Second session & $\begin{array}{l}\text { Discovering and investigating treatment methods and evaluating their effectiveness, discussing the temporary and } \\
\text { ineffectiveness of treatments using allegory, receiving feedback, and giving assignments }\end{array}$ \\
\hline Third session & $\begin{array}{l}\text { Assisting clients in identifying ineffective control strategies and realizing their futility, accepting painful personal events without } \\
\text { further conflict using allegory, receiving feedback, and giving assignments }\end{array}$ \\
\hline Fourth session & $\begin{array}{l}\text { Explanation about avoiding painful experiences and being aware of their consequences, teaching acceptance steps, changing } \\
\text { language concepts using allegory, teaching relaxation, receiving feedback, and giving assignments }\end{array}$ \\
\hline Fifth session & $\begin{array}{l}\text { Introducing a three-dimensional behavioral model to express the common relationship between behavior/emotions, } \\
\text { psychological functions, and observable behavior, as well as discussing attempts to change behavior based on the developed } \\
\text { model, receiving feedback, and giving assignments }\end{array}$ \\
\hline Sixth session & $\begin{array}{l}\text { Explaining the concepts of role and context, observing oneself as a context and making contact with oneself using allegory, being } \\
\text { aware of different sensory perceptions, and separating the senses that are part of the mental content; receiving feedback, and } \\
\text { giving assignments }\end{array}$ \\
\hline Seventh session & $\begin{array}{l}\text { Explaining the concept of values, encouraging change, empowering clients for a better life, practicing focus, receiving feedback, } \\
\text { and giving assignments }\end{array}$ \\
\hline Eighth session & \begin{tabular}{l} 
Teaching commitment to action and identifying behavioral plans as per values, summarizing sessions, conducting post-tests \\
\hline
\end{tabular}
\end{tabular}

Table 3. Descriptive variables of this study for the three under-test groups at pre-test and post-test levels

\begin{tabular}{|c|c|c|c|c|}
\hline Variables & Categories & ET group & ACT group & Control group \\
\hline & & $M(S D)$ & $M(S D)$ & $M(S D)$ \\
\hline \multirow{2}{*}{ Hope } & Pre-test & $28.54(4.46)$ & $27.63(5.34)$ & $19.52(3.54)$ \\
\hline & Post-test & $38.65(4.35)$ & $33.64(4.24)$ & $20.31(2.35)$ \\
\hline \multirow{2}{*}{ Irrational beliefs } & Pre-test & $148.56(8.54)$ & $146.46(9.72)$ & $153.46(10.31)$ \\
\hline & Post-test & $129.43(9.56)$ & $132.43(11.45)$ & $151.90(8.43)$ \\
\hline
\end{tabular}

Note. ACT: Acceptance and Commitment Therapy; ET: Existential Therapy; M: Mean; SD: Standard Deviation

Table 4. Statistics for the normality of data distribution

\begin{tabular}{|c|c|c|c|c|c|}
\hline Variables & Group & Tilt & Elongation & Shapiro-Wilk & p-value \\
\hline & ET & 1.6 & 1.6 & 0.953 & 0.514 \\
\hline \multirow[t]{3}{*}{ Hope } & ACT & 1.3 & 0.6 & 0.927 & 0.356 \\
\hline & Control & 1.9 & 0.5 & 0.980 & 0.424 \\
\hline & ET & 0.8 & 1.6 & 0.879 & 0.398 \\
\hline \multirow[t]{2}{*}{ Irrational beliefs } & ACT & 1.4 & 1.7 & 0.657 & 0.413 \\
\hline & Control & 0.5 & 0.4 & 0.989 & 0.467 \\
\hline
\end{tabular}

Note. ACT: Acceptance and Commitment Therapy; ET: Existential Therapy

energy); (ii) Pathways (i.e., planning to accomplish goals). Questions are scored on a Likert scale, i.e., from 1 (definitely false) to 4 (definitely true). Questions 3, 5, 7, and 11 are not scored. Suitable validity and reliability have been confirmed for the Persian version of the Adult Hope Scale (Cronbach's alpha: $0.70-0.89)[19]$.

\section{Four-factor irrational beliefs test-ahvaz (4IBT-A)}

The 4IBT-A in Iranian society based on the 10-item Jones Irrational Beliefs Test using factor analysis wasdevelopedby [20]. It includes 40 questions that are scored on a 5-point Likert scale from one (strongly disagree) to five (strongly agree). They also implemented the Cronbach's alpha method and estimated the test reliability for demand for approval, helplessness with change, emotional irresponsibility, problem avoidance, and the total test at $0.68,0.77,0.68,0.59$, and 0.86 , respectively.

\section{Statistical Analysis}

The data were analyzed by SPSS v25 software at the significance level of $p<0.05$. Statistical analysis was conducted using descriptive statistics, such as mean and standard deviation and multivariate analysis of covariance (MANCOVA). The Shapiro-Wilk test was also used for testing normality.

\section{RESULTS}

Table 3 presents the descriptive variables of this study for the three test groups. Before analyzing the covariance, we investigated the assumptions of this test. The normality of data distribution is presented in Table 4. As you can see, the variance of the hope in the pre-test and post-test of all three groups ranged from -2 to +2 . Shapiro-Wilk test showed that the hope variable is normal in all groups. According to the significance level of Levene's test, the assumption of homogeneity of variances was rejected (Table 5). But, since the groups were the same size, they were resistant to the former violation, and parametric analyses could be performed. For all research variables, the value of test statistics of interaction between pre-test and post-test groups was statistically significant, and the condition of regression slope balance for analysis of covariance was also established (Table 6). As can be seen, the difference between the mean score of hope and irrational beliefs of the subjects between the control group and both ET and ACT groups is significant. Therefore, it can be said that the two methods of ET and ACT had a major effect on hope and irrational beliefs. Also, there was a significant difference in the effectiveness of ET and ACT in increasing hope (but not irrational beliefs) in male prisoners (Table 7). 
Table 5. Investigation of independence and \& homogeneity of regression slopes assumption (hope \& irrational beliefs are dependent variables)

\begin{tabular}{|c|c|c|c|c|c|c|}
\hline Variables & Source of change & Total squares & df & Mean squares & $\mathbf{F}$ & p-value \\
\hline & Pre-test & 82.24 & 1 & 41.12 & 36.51 & $<0.001$ \\
\hline \multirow[t]{3}{*}{ Hope } & Group interaction $\times$ Pre-test & 38.25 & 2 & 24.53 & 0.29 & 0.265 \\
\hline & Error & 76.42 & 30 & 31.24 & & \\
\hline & Pre-test & 109.35 & 1 & 54.76 & 33.14 & $<0.001$ \\
\hline \multirow[t]{2}{*}{ Irrational beliefs } & Group interaction $\times$ Pre-test & 41.13 & 2 & 31.35 & 0.33 & 0.176 \\
\hline & Error & 62.47 & 30 & 29.35 & & \\
\hline
\end{tabular}

Note. df: Degree of Freedom

Table 6. Test of between-subject effects (hope \& irrational beliefs are dependent variables)

\begin{tabular}{|c|c|c|c|c|c|c|c|}
\hline Variables & Source of change & Total squares & df & Mean squares & $\mathbf{F}$ & p-value & Squares \\
\hline & Pre-test & 1112.984 & 1 & 1112.984 & 38.11 & $<0.001$ & 0.221 \\
\hline \multirow[t]{3}{*}{ Hope } & Group & 3081.913 & 2 & 1027.304 & 35.08 & $<0.001$ & 0.314 \\
\hline & Error & 1024.718 & 32 & 29.76 & & & \\
\hline & Pre-test & 17689.984 & 1 & 17689.984 & 31.42 & $<0.001$ & 0.312 \\
\hline \multirow[t]{2}{*}{ Irrational beliefs } & Group & 2567.246 & 2 & 1251.357 & 29.42 & $<0.001$ & 0.287 \\
\hline & Error & 2415.536 & 32 & 34.14 & & & \\
\hline
\end{tabular}

Note. df: Degree of Freedom

Table 7. Pair comparison of subjects' hope and irrational beliefs in three groups

\begin{tabular}{|c|c|c|c|c|c|}
\hline Variables & Group i & Group j & Mean differentiation & SD & p-value \\
\hline \multirow{6}{*}{ Hope } & \multirow{2}{*}{ Control } & $\mathrm{ACT}$ & -13.33 & 1.647 & $<0.001$ \\
\hline & & ET & -18.42 & 1.467 & $<0.001$ \\
\hline & \multirow{2}{*}{$\mathrm{ACT}$} & Control & 13.33 & 2.246 & $<0.001$ \\
\hline & & ET & -5.04 & 2.551 & 0.023 \\
\hline & \multirow{2}{*}{ ET } & Control & 18.42 & 2.245 & $<0.001$ \\
\hline & & ACT & 5.04 & 1.425 & 0.023 \\
\hline \multirow{6}{*}{ Irrational beliefs } & \multirow{2}{*}{ Control } & $\mathrm{ACT}$ & 8 & 1.312 & $<0.001$ \\
\hline & & ET & 5.10 & 1.567 & $<0.001$ \\
\hline & \multirow{2}{*}{$\mathrm{ACT}$} & Control & -8.10 & 1.415 & $<0.001$ \\
\hline & & ET & -2.10 & 2.979 & 0.231 \\
\hline & \multirow{2}{*}{ ET } & Control & -5.10 & 2.536 & $<0.001$ \\
\hline & & ACT & 2.10 & 1.417 & 0.231 \\
\hline
\end{tabular}

Note. ACT: Acceptance and Commitment Therapy; ET: Existential Therapy; SD: Standard Deviation

\section{DISCUSSION}

The results of data analysis showed that, compared to the control group, the impacts of ET and ACT are significant on hope and irrational beliefs in male prisoners (with the greater effectiveness of ET in increasing hope compared to ACT). These findings were consistent with the studies of $[15,20]$. Concerning an increase in hope by ACT, people are taught to observe their thoughts and feelings without judgment as simple mental events. In other words, they are transient, they come and go, and they should not be perceived as part of people or as a reflection of reality. This kind of attitude towards cognitions related to depression prevents the intensification of negative thoughts and the creation of rumination. Repeating each exercise to form a skill is a crucial factor in maintaining the effects of ACT on increasing hope [21]. In fact, enabling participants to recognize their mental process and deliberately alter it to any other mental form is the main goal of ACT. Therefore, the effects of this treatment appear on various aspects of a person's psychological states after being learned skillfully. Our minds interpret events and cause reactions and feelings to persist, and people who are prone to depression constantly focus on the sad and negative thoughts that lead to more anxiety. ACT helps people better understand themselves and experience a non-judgmental, receptive, confident, patient, and kind attitude to make them aware of relationships with others, increase their social interactions, and affect their interpersonal behaviors [22].

ACT is inversely related to rumination and depressive symptoms. It raises emotions dramatically and allows people to experience a wide range of thoughts and feelings in their minds without experiencing emotional turmoil [18]. It can also be said that ET affects different aspects of worldview, way of thinking, and how to deal with one's problems and emotions. ET does not have a negative attitude towards life problems but rather considers them as an integral part of life. It helps people accept their problems to understand their lives better and take responsibility to continue living. If the quality of life is reduced, the person won't take responsibility and blame others that can affect their lives [15].

Furthermore, the results of data analysis showed that there was no difference in the effectiveness of ET and ACT on irrational beliefs. These findings were consistent with studies of [23-25]. To help clients go beyond their rumination patterns, ACT provides variables such as acceptance, non-judgment, flexibility, and active and problem-oriented responses, reduces negative emotions related to the experience of unpleasant thoughts, increase anxiety tolerance, train to identify and replace dysfunctional and negative beliefs, and raise people's awareness of the present moment and place. It also helps clients gain more knowledge about the forces associated with relapse in their mental and physical processes, change their 
cognitive and processing systems, not have difficulty controlling their thoughts and emotions and disturb their signs and symptoms, be aware of their unpleasant thoughts, increase their tolerance, and be able to prepare themselves to face negative thoughts. This allows the person to reduce the impact of negative thoughts on their mood and prevents them from experiencing depression despite the presence of negative thoughts [23].

One of the characteristics of people with irrational beliefs is cognitive integration occurring when a person considers his thoughts to be correct; many problems arise from focusing on the texture of depressive thoughts $[15,26]$. Therefore, focusing on the context related to thoughts and feelings that lead to undesirable behaviors was targeted at the subjects, which reduced the participants' credibility and flexibility. Thus, the use of metaphors, exercises, contradictions, and language conventions of ACT in this context was used to describe that the mind cannot have all the answers and distinguishes between itself and its thoughts. Cognitive disruption skills worked on judgments, interpretations, and predictions; in fact, the hidden function of language was revealed to the subjects, and the authorities were instructed to separate themselves from their thoughts, emotions, and feelings [27].

Ruminants and repetitive thought patterns are characteristics of depressed people which make them lose touch with the present moment and take them into a negative past or future. A depressed person may want to have a warm relationship but does not go out and meet people because he/she may be ruminating over how people have beaten $\mathrm{him} /$ her. Although rumination, compared to anxiety, seems to be more focused on the past, the high rate of comorbidity of depression and anxiety disorders indicates that depressed clients are often preoccupied with the future [27]. One of the dimensions of ACT is being in the present, which was emphasized in therapy sessions so that the subjects could realize their depressive thoughts. In this regard, meditation was used to enable them to return to the present moment and separate from rumination, whereby they could develop the potential to change self and reduce irrational beliefs [11,15].

The existential approach emphasizes that mortality and transience are the main features of life and a key factor in its meaning. Following the group process, the individual reaches the awareness that although the real conditions of life cannot be changed, the ways of coping with it can be altered from despair and fruitlessness (as the components of lack of mental health) to flourishing and excellence of individuality by giving meaning to how the self is. People face new challenges related to independence, education, social communication, being away from family, and other issues imposed on them by a new environment. These changes may lead to increased stress, high prevalence of adaptation problems, and decreased mental health and overall performance. Throughout the process, the group identified and explored these issues, concerns, values, and perspectives on themselves and their lives and made efforts to change them. Therefore, the most prominent feature of this approach is the emphasis on the therapeutic relationship and its role in causing a change in clients [11,28].

The research limitations were attributed to the follow-up stage due to lack of cooperation and access of the subjects, inability to examine and control variables such as a history of substance use and psychiatry, and disregarding other assessment methods such as interview.

\section{CONCLUSIONS}

The aim of this study was to compare the effectiveness of ET and ACT in increasing hope and diminishing irrational beliefs of male prisoners. The results of data analysis showed that, compared to the control group, the effects of ET and ACT were significant on hope and irrational beliefs, with the greater effectiveness of ET in elevating hope compared to ACT. However, we suggest further studies to have a better vision on the effectiveness of these two therapeutic approaches among the prison population.

Author contributions: All authors have sufficiently contributed to the study, and agreed with the results and conclusions.

Funding: No funding source is reported for this study.

Declaration of interest: No conflict of interest is declared by authors. Ethical considerations and human subjects' protection: The study was approved by the ethics committee of the Islamic Azad University, Mashhad Branch (IR.IAU.MSHD.REC.1399.131), and all procedures were in accordance with the latest version of the Declaration of Helsinki. Prior to participation, written informed consent was obtained from all participants and their parents/legal guardians after a comprehensive explanation of the study procedures.

\section{REFERENCES}

1. Baybutt, M, Dooris, M, Farrier, A. Growing health in UK prison settings. Health Promot Int. 2019;34(4):792-802. https://doi.org/10.1093/heapro/day037 PMid:29850822 PMCid:PMC6735902

2. De Berardis D, Marini S, Serroni N, lasevoli F, Tomasetti C, de Bartolomeis A, et al. Targeting the noradrenergic system in posttraumatic stress disorder: A systematic review and meta-analysis of prazosin trials. Curr Drug Targets. 2015;16(10):1094-106. https://doi.org/10.2174/1389450116 666150506114108 PMid:25944011

3. De Berardis D, Vellante F, Fornaro M, Anastasia A, Olivieri L, Rapini G, et al. Alexithymia, suicide ideation, affective temperaments and homocysteine levels in drug naïve patients with post-traumatic stress disorder: an exploratory study in the everyday 'real world'clinical practice. Int J Psychiatry Clin Pract. 2020;24(1):83-7. https://doi.org/10.1080/13651501.2019.1699575 PMid: 31829763

4. Khosravi M. The mediating role of alexithymia in the association between attachment styles and borderline personality symptomatology. Health Psychol Res. 2020;8(2):8894. https://doi.org/10.4081/hpr.2020.8894 PMid:33210014 PMCid:PMC7649641

5. Fazel, S, Hayes, AJ, Bartellas, K, Clerici M, Trestman R. Mental health of prisoners: Prevalence, adverse outcomes, and interventions. Lancet Psychiatry. 2016;3(9):871-81. https://doi.org/10.1016/S2215-0366(16)30142-0 PMid: 27426440 PMCid:PMC5008459

6. Gee, J, Loewenthal, D, Cayne, J. Psychotherapy and despair in the prison setting. Int J Prison Health. 2015;11(3):141-56. https://doi.org/10.1108/IJPH-11-2014-0042 PMid:26277922

7. Kristofersson, GK, Kaas, MJ. Stress management techniques in the prison setting. J Forensic Nurs. 2013;9(2):111-9. https://doi.org/10.1097/JFN.0b013e31827 a5a89 PMid:24158133

8. Snyder CR, Lopez SJ. Handbook of positive psychology. New York, NY: Oxford University Press; 2001. 1460 p. p. 
9. Acharya T, Agius M. The importance of hope against other factors in the recovery of mental illness. Psychiatr Danub. 2017;29(Suppl 3):619-22.

10. Peterson SJ, Gerhardt MW, Rode JC. Hope, learning goals, and task performance. Pers Individ Dif. 2006;40(6):1099109. https://doi.org/10.1016/j.paid.2005.11.005

11. van Deurzen, E. Existential counselling \& psychotherapy in practice. 3rd ed. New York: SAGE; 2012. 264 p. p. https://doi.org/10.4135/9781473983205

12. Ozer EA, Akgun OE. The effects of irrational beliefs on academic motivation and academic self-efficacy of candidate teachers of computer and instructional technologies education department. Procedia Soc Behav Sci. 2015;197:1287-92. https://doi.org/10.1016/j.sbspro. 2015.07.401

13. Vos J, Craig M, Cooper M. Existential therapies: A metaanalysis of their effects on psychological outcomes. J Consult Clin Psychol. 2015;83(1):115-28. https://doi.org/10. 1037/a0037167 PMid:25045907

14. Udo C, Melin-Johansson C, Danielson E. Existential issues among health care staff in surgical cancer care-discussions in supervision sessions. Eur J Oncol Nurs. 2011;15(5):44753. https://doi.org/10.1016/j.ejon.2010.11.010 PMid: 21159553

15. Ziaee A, Nejat H, Amarghan HA, Fariborzi E. Existential therapy versus acceptance and commitment therapy for feelings of loneliness and irrational beliefs in male prisoners. Eur J Transl Myol. 2022;32(1):10271. https://doi.org/10.4081/ejtm.2022.10271 PMid:34818880

16. Bohlmeijer ET, Lamers SM, Fledderus M. Flourishing in people with depressive symptomatology increases with acceptance and commitment therapy. Post-hoc analyses of a randomized controlled trial. Behav Res Ther. 2015;65:101-6. https://doi.org/10.1016/j.brat.2014.12.014 PMid:25596344

17. Dindo L, Van Liew JR, Arch JJ. Acceptance and commitment therapy: a transdiagnostic behavioral intervention for mental health and medical conditions. Neurotherapeutics. 2017;14(3):546-53. https://doi.org/10.1007/s13311-0170521-3 PMid:28271287 PMCid:PMC5509623

18. Twohig MP, Levin ME. Acceptance and commitment therapy as a treatment for anxiety and depression: a review. Psychiatr Clin North Am. 2017;40(4):751-70. https://doi.org/10.1016/j.psc.2017.08.009 PMid:29080598

19. Sharif Nia H, Rahmatpour P, She L, Abounoori M, Maddah MM, Sharif SP, Mohammadinezhad M. Psychometric evaluation of Persian version of hope scale in Iranian patients with cancer. J Nurs Meas. 2021;JNM-D-20-00043. https://doi.org/10.1891/JNM-D-20-00043 PMid:34518400
20. Mahmoudpour A, Rayesh N, Ghanbarian E, Rezaee M. Effectiveness of acceptance and commitment therapy (ACT) on emotional regulation and loneliness of divorced women in Iran. J Marital Fam Ther. 2021;47(4):831-42. https://doi.org/10.1111/jmft.12492 PMid:33675048

21. White R, Gumley A, McTaggart J, Rattrie L, McConville D, Cleare $S$, et al. A feasibility study of acceptance and commitment therapy for emotional dysfunction following psychosis. Behav Res Ther. 2011;49(12):901-7. https://doi.org/10.1016/j.brat.2011.09.003 PMid:21975193

22. Masuda A, Hayes SC, Fletcher LB, Seignourel PJ, Bunting K, Herbst SA, et al. Impact of acceptance and commitment therapy versus education on stigma toward people with psychological disorders. Behav Res Ther. 2007;45(11):276472. https://doi.org/10.1016/j.brat.2007.05.008 PMid: 17643389

23. Walser RD, Garvert DW, Karlin BE, Trockel M, Ryu DM, Taylor CB. Effectiveness of acceptance and commitment therapy in treating depression and suicidal ideation in Veterans. Behav Res Ther. 2015;74:25-31. https://doi.org/10.1016/ j.brat.2015.08.012 PMid:26378720

24. Graham CD, Gouick J, Krahe C, Gillanders D. A systematic review of the use of acceptance and commitment therapy (ACT) in chronic disease and long-term conditions. Clin Psychol Rev. 2016;46:46-58. https://doi.org/10.1016/j.cpr. 2016.04.009 PMid:27176925

25. McCracken LM, Gutiérrez-Martínez O. Processes of change in psychological flexibility in an interdisciplinary groupbased treatment for chronic pain based on acceptance and commitment therapy. Behav Res Ther. 2011;49(4):267-74. https://doi.org/10.1016/j.brat.2011.02.004 PMid:21377652

26. Jefferson A, Bortolotti L, Kuzmanovic B. What is unrealistic optimism? Conscious Cogn. 2017;50:3-11. https://doi.org/ 10.1016/j.concog.2016.10.005 PMid:27815016 PMCid: PMC5380125

27. Hood Morris LE. A spiritual well-being model: Use with older women who experience depression. Issues Ment Health Nurs. 1996;17(5):439-55. https://doi.or/10.3109/ 01612849609009412 PMid:8920342

28. van Deurzen E, Craig E, Lägle A, Schneider KJ, Tantam D, du Plock S. The Wiley handbook of existential therapy. Chichester, UK: John Wiley \& Sons Ltd; 2019. 827 p. p. https://doi.org/10.1002/9781119167198 